Yeshwant Sainath, Varghese K, and Raghavan N. (2018). "Framework for Progressive Evaluation of Lean Construction Maturity using Multi-Dimensional Matrix." In: Proc. 26 th Annual Conference of the International. Group for Lean Construction (IGLC), González, V.A. (ed.), Chennai, India, pp. 370-380. DOI: doi.org/10.24928/2018/0416. Available at: www.iglc.net.

\title{
FRAMEWORK FOR PROGRESSIVE EVALUATION OF LEAN CONSTRUCTION MATURITY USING MULTI-DIMENSIONAL MATRIX
}

\author{
Yeshwant Sainath ${ }^{1}$, Koshy $\operatorname{Varghese}^{2}$, and Raghavan $\mathbf{N}^{3}$
}

\begin{abstract}
Lean is a culture-based management system essentially aimed at waste elimination, thereby creating value for the customer. It is a transformation journey and to evaluate the progress on this journey at any time, the achieved state of maturity has to be assessed. We argue that Lean Construction management spans three stages or phases - Physical (Activity-based) Manifestation, Behavioral (Culture-based) Manifestation and Strategic (Long-term) Manifestation. To evaluate the progress on this journey and assess the state of Lean maturity achieved across a project or the entire organization at any stage, a host of factors needs to be considered.

The distinctive factors relating to each of the above three stages are initially identified by literature survey and interviews. These factors are then assigned with different individual weights through findings from a detailed questionnaire survey. A weighted factor model is then developed to assess the overall maturity at project and organizational levels. The Lean scores for the various factors are shown on a Spider Radar and a bar chart and overall maturity level is plotted on a normative Lean maturity progression curve spanning across the three stages.

The model was developed based on data collected from 25 Lean practitioners across six organizations, which are implementing Lean construction in their sites. The model was then applied to projects of four different organizations and the Lean Construction Maturity Ratings were calculated. These scores were then discussed with experts to validate whether the scores appropriately reflected, in an overall qualitative sense, the Lean maturity of the projects surveyed. In view of the low level of spread of Lean practices across the Industry in this country, assessment of Lean maturity across an entire organization has not been taken up so far.
\end{abstract}

1 Student, Dept. of Civil Engineering, Indian Institute of Technology Madras, Chennai, India, yeshwant0311@gmail.com

2 Professor, Dept. of Civil Engineering, Indian Institute of Technology Madras, Chennai, India,koshy@iitm.ac.in

3 Professor of Practice, Dept. of Civil Engineering, Indian Institute of Technology Madras, Chennai, India,nraghavan@iitm.ac.in 


\section{KEYWORDS}

Lean Culture, Lean Construction Maturity level, Normative Progression Curve, Questionnaire Survey, Lean practices.

\section{INTRODUCTION}

Over the last four decades, there has been a growing focus in both manufacturing and construction organizations on implementation and development of improvement techniques to increase benefits and reduce costs. The construction industry around the world faces a critical challenge to improve its innovation and productivity (Larsson et al., 2013) to be at par with the manufacturing industry as manufacturing sector has been more able to progress with innovation. Indian Construction is in its nascent stage of Lean adaptation and acceptance of Lean across various organizations can be best evaluated by determining the current state of maturity to determine the strengths and weaknesses in the Lean Construction implementation process (Bernardo M. B. S. Etges, 2013).

A framework is proposed in this paper covering various aspects of Lean in construction that will assist organizations to assess their current state and to know where they stand in the overall journey to Lean perfection.

\section{LITERATURE REVIEW}

In this section the information and data collected on a review of the various Lean maturity assessment models proposed by various earlier investigators are discussed.

Creating a Lean culture in the organization invariably requires behavioral changes in all organizational levels. On one hand, being Lean should be part of the core business strategy and should be considered in any important and strategic decision made by the company (Womack \& Jones, 1996). On the other hand, equipping employees with appropriate tools and techniques and empowering them to use a suitable set of those techniques for managing construction can make a significant impact on an organization's performance (Shah \& Ward, 2003). Accordingly the Lean usage will evolve from basic Operational or Physical levels through an evolution in Behavioral levels to a permeating Strategic level.

The concept of maturity models originated from quality management perspectives that describe quality improvement through a five-level maturity scale (Crosby 1979). Such a maturity model is generic and can be applied across any industry; but in order to operationalize it for a particular industry, two additional developments need to happen: Developing factors to define each maturity level; and developing a roadmap for strategy to enhance maturity.

A maturity model that defines the various applicable factors and improvement opportunities is very beneficial in bringing major transformation (Nesensohn, et al., 2014). Nesensohn et al. (2013a, 2014) and Nesensohn (2017) also show a detailed framework comprising various maturity levels, "ideal statements" and corresponding Factors, which enable the measure of current maturity of any construction project. The UK Highway Agency has developed an in-house Lean Maturity Assessment Toolkit 
(HALMAT), based on the Lean Enterprise Self- Assessment Tool (LESAT) developed by the aerospace industry at the Massachusetts Institute of Technology (MIT).

Below are a few of the Lean Maturity Assessment Instruments culled out from available literature tabulated with their purpose and scope of assessment.

Table 1: Lean Maturity Assessment Instruments

\begin{tabular}{|c|c|c|c|}
\hline $\begin{array}{l}\text { Author } \\
\text { Name }\end{array}$ & $\begin{array}{c}\text { Instrument } \\
\text { name }\end{array}$ & Purpose & Scope of Assessment \\
\hline $\begin{array}{l}\text { Nesensohn } \\
\text { et al.,2014, } \\
2015,2017\end{array}$ & $\begin{array}{c}\text { Lean } \\
\text { Constructio } \\
\text { n Maturity } \\
\text { Model } \\
\text { (LCMM) }\end{array}$ & $\begin{array}{l}\text { It provides } \\
\text { organizations with } \\
\text { factors, maturity } \\
\text { levels and ideal } \\
\text { statements which } \\
\text { help in assessment } \\
\text { of the current state } \\
\text { in Lean } \\
\text { Construction } \\
\text { Journey }\end{array}$ & $\begin{array}{l}\text { It comprises } 11 \text { key factors: } \\
\text { 1. Lean leadership, } \\
\text { 2. Customer focus, } \\
\text { 3. Way of thinking, } \\
\text { 4. Culture \& behavior, } \\
\text { 5. Competencies, } \\
\text { 6. Improvement enablers, } \\
\text { 7. Processes \& tools, } \\
\text { 8. Change, } \\
\text { 9. Work environment, } \\
\text { 10. Business results, } \\
\text { 11. Learning and competency } \\
\text { development. }\end{array}$ \\
\hline $\begin{array}{c}\text { Donovan, } \\
2015\end{array}$ & $\begin{array}{l}\text { Lean Manu- } \\
\text { facturing: } \\
\text { Performanc } \\
\text { e Evaluation } \\
\text { Audit }\end{array}$ & $\begin{array}{l}\text { This tool provides a } \\
\text { checklist of various } \\
\text { parameters for the } \\
\text { assessment of an } \\
\text { organization's } \\
\text { current status in } \\
\text { adopting Lean } \\
\text { Manufacturing } \\
\text { Criteria. }\end{array}$ & $\begin{array}{l}\text { It includes a number of yes/no questions } \\
\text { focused on various fields important in the } \\
\text { Lean Management approach:: } \\
\text { 1. Process planning and control, } \\
\text { 2. Management and leadership, } \\
\text { 3. Quality control and planning, } \\
\text { 4. TPM, } \\
\text { 5. Suppliers, } \\
\text { 6. Selected Lean techniques, } \\
\text { 7. Customer focus, and } \\
\text { 8. Performance improvement }\end{array}$ \\
\hline $\begin{array}{c}\text { Department } \\
\text { of } \\
\text { Transport, } \\
\text { UK }\end{array}$ & $\begin{array}{l}\text { Highways } \\
\text { Agency } \\
\text { Lean } \\
\text { Maturity } \\
\text { Assessment } \\
\text { Toolkit - } \\
\text { HALMAT }\end{array}$ & $\begin{array}{l}\text { The purpose of } \\
\text { using the in-house } \\
\text { developed } \\
\text { assessment tool is } \\
\text { to provide the } \\
\text { organization with a } \\
\text { structured means of } \\
\text { assessing where it } \\
\text { is in the journey of } \\
\text { Lean. }\end{array}$ & $\begin{array}{l}\text { Areas of coverage of the assessment } \\
\text { toolkit: } \\
\text { 1. Strategic use of Lean } \\
\text { 2. Financial, information, and } \\
\text { procurement systems } \\
\text { 3. Lean leadership } \\
\text { 4. People development } \\
\text { 5. Lean structure and behavior } \\
\text { 6. Collaborative working } \\
\text { 7. Delivery of value } \\
\text { 8. Standard work } \\
\text { 9. Process flow } \\
\text { 10. Process control and quality assurance }\end{array}$ \\
\hline
\end{tabular}




\section{RESEARCH METHODOLOGY Basic Premises}

i) As Lean Maturity increases, the predominant outlook in projects shifts in 3 stages from Physical Practices through Behavioral Practices to Strategic Practices. While the lower practices are still essential, the emphasis shifts to the higher practices (Fig. 2). The interview respondents have also opined that with good adoption of Physical practices in Projects, a tendency to follow Behavioral Practices sets in, further maturing on to adopting Strategic outlook by and by. Though the journey is long, there is a continuous progression.

ii) Lean Maturity can be assessed on the basis of certain practices and concepts being implemented at the Project.

iii) The critical Lean Concepts and Practices can be prioritized for the three stages by observations in projects and taking inputs from expert Lean practitioners.

The following stepwise methodology approach is used in the process of developing the proposed framework based on the above premises:

- Step I - Exploratory study (Literature review \& Lean academic expert opinions). This helped in identifying the various factors that can define the Lean maturity level based on which a preliminary framework was developed. The factors were divided into three stages (Physical, Behavioral \& Strategic) which also corresponds to some degree with an organization's three tier management system (Lower, Middle \& Top).

- $\quad$ Step II - Industry Lean practitioner opinions/input: This helped in garnering handson experience from the industry experts who are practicing Lean tools \& approaches, to identify the various factors in detail and helped to develop a Lean Evaluation Checklist. (Ref. Figure2 for a typical Lean Evaluation Checklist.)

- $\quad$ Step III - Questionnaire Survey: A five-point Likert Scale survey based on Strongly Disagree to Strongly Agree was conducted among Lean practitioners from various organizations to get their responses to identify the various Concepts and Practices which would define Lean maturity and a concept of Relative Importance Index (RII) was adopted to derive the weights for each factor.

Along with the survey responses, semi-structured interviews were conducted with various Lean practitioners across the spectrum of Clients, Consultants and Contractors to check whether the compliance to processes could be quantifiable on a binary scale, and whether the stage wiseapproach is valid. The overall response was quite positive. Again, it was important to know whether this model will help in improving the current state of maturity. Knowing the areas of weaknesses or lacunae, as seen from the Lean Evaluation Checklist, practitioners can identify the areas where they have to improve in future.

- $\quad$ Step IV - Development of Framework: A framework was developed linking the various Factors, Weights and Development Stages. 
- $\quad$ Step V - Case Study for validation: Testing of the framework was done in a few organizations. Further testing is required to tone up and further improve the model.

\section{PROPOSED FRAMEWORK}

This research is aimed at capturing qualitative as well as quantitative data in the form of survey responses and semi-structured interviews to understand the various factors which define the degree of Lean Construction maturity and based on these data the framework is developed. Thereafter the concerned project sites were visited, relevant data collected by observations, followed by study of project documents and queries with the project personnel. Then this data was fed into this framework and the Lean Construction Maturity Rating (LCMR) determined. This index is also validated, though in a subjective manner, on the basis of overall observations of project sites and broad queries. Figure 1 illustrates the components of this model.

\begin{tabular}{|c|c|c|c|c|}
\hline \multirow[t]{3}{*}{$\begin{array}{c}\text { Lean Evaluation } \\
\text { Checklist (Yes/No } \\
\text { based scoring) }\end{array}$} & \multirow[t]{3}{*}{$\begin{array}{l}\text { Practice Score (PS) } \\
\text { (Normalized to 10) }\end{array}$} & $\begin{array}{l}\text { Consolidated Stage Score } \\
\sum(\mathrm{PS} \times \mathrm{CWf}) / \Sigma(\mathrm{CWf})\end{array}$ & $\underset{\text { Consolidated Stage }}{\stackrel{\text { Score (CSS) }}{\longrightarrow}}$ & $\begin{array}{c}\text { Lean Construction } \\
\text { Maturity Rating } \\
\sum(\text { CSS x STF })\end{array}$ \\
\hline & & $\begin{array}{l}\text { Ooncept Weight } \\
\text { factor (CWf) }\end{array}$ & \multirow[t]{2}{*}{$\begin{array}{r}\text { Sta } \\
\mathrm{Fa}\end{array}$} & $\begin{array}{l}\text { Weight } \\
\text { or (STF) }\end{array}$ \\
\hline & & $\begin{array}{c}\text { Questionnaire Survey } \\
\text { Responses (RII tool applied) }\end{array}$ & & $\begin{array}{l}\text { Lean Maturity } \\
\text { Progressive Curve }\end{array}$ \\
\hline
\end{tabular}

Figure 1: Framework for assessing LCMR

We argue that the journey of any organization towards perfection in Lean will cover different types of practices in three typical stages and every construction project would also have similar stages: Physical practices stage, Behavioral practices stage, Strategic practices stage. This was also got vetted through the interviews. In the first stage various Lean tools will be practiced with emphasis on Physical progress. In the second stage with the steady onset of a Lean Culture, Behavioral practices will start becoming dominant. In the third and final stage Lean culture would have permeated the whole set-up and Lean would be a Strategic concept covering all planning and implementation, with the highest Lean Maturity. Though the first stage is common in Projects and the next two stages in the overall organization, the progression towards higher stages is evident in projects with sustained practice of Lean.

Accordingly certain Lean Concepts are identified for each of the three Stages and for each Concept certain Practices are identified along with Attributes which define the Practice in some detail, to compile a Lean Evaluation Checklist (Figure 2). As the first step in the LCMR determination, evaluation of Project is assessed for perfection in each of the Practices, based on certain defined Attributes, on a Binary Mode, with "Yes" or "No" for whether each Practice is done or not done on the Project. The depth of practice and longevity of practice are also considered in an overall sense. Then the percentage of Yes's obtained for the various Practices in each Concept is normalized over a base of 10 to obtain the Lean Practice Score (PS) for that Concept. 


\begin{tabular}{|c|c|c|c|}
\hline Concepts & Attributes & Processes & $\mathrm{Y} / \mathrm{N}$ \\
\hline \multirow{6}{*}{ Collaborative Working } & Meeting \& MOM & $\begin{array}{l}\text { Are all the concerned stakeholders part of meeting \& MOM been shared to all the } \\
\text { concerned parties on regular basis? }\end{array}$ & $Y$ \\
\hline & Partnering & $\begin{array}{l}\text { Is Trust been generated for partnering with existing S/C \& vendors instead of floating bid } \\
\text { for new parties and wasting time \& resources? }\end{array}$ & $\mathrm{N}$ \\
\hline & $\begin{array}{l}\text { Evaluation of } S / C \& \\
\text { Vendor }\end{array}$ & $\begin{array}{l}\text { Is Past Performance Evaluation been done before getting Vendor \& } \mathrm{S} / \mathrm{C} \text { on board and } \\
\text { periodic evalution is recorded too? }\end{array}$ & $\mathrm{N}$ \\
\hline & $\begin{array}{l}\text { Coordinated Drawing } \\
\text { Sharing }\end{array}$ & $\begin{array}{l}\text { Is coordinated drawing been shared with all the concerned parties - accepted \& signed by } \\
\text { them before commencement of activities? }\end{array}$ & $\mathrm{Y}$ \\
\hline & Change Notes Sharing & $\begin{array}{l}\text { Are change notes been shared with all the concerned parties - accepted \& signed by them } \\
\text { before commencement of activities? }\end{array}$ & Y \\
\hline & Contractual Stipulation & $\begin{array}{l}\text { Is contractual Clause w.r.t Lean construction methodology been added before getting on } \\
\text { board all the Stakeholdes - Subcontractors \& Vendors? }\end{array}$ & $\mathrm{Y}$ \\
\hline
\end{tabular}

Figure 2: Lean Evaluation Checklist - Typical Concepts, Attributes and Processes

In parallel a five point Likert Scale survey has been carried out covering a large number of Lean practitioners from various Projects to identify Lean concepts and practices which are most critical to attain Lean Maturity and the Lean Practices for each Concept are accordingly ranked in terms of importance. Then using a Relative Importance Index (RII) statistical approach conducted over the questionnaire responses, RII scores are derived for each Concept and they are seen to vary from 0.75 to 0.95 , with the higher scores indicating higher relevance. Hence to enable further processing, the RII scores are converted to Concept Weightsfactor (CWf) as per following Table 2:

Table 2: RII and Weights distribution

\begin{tabular}{|c|c|c|c|c|}
\hline RII & $>\mathbf{0 . 9 0}$ & $\mathbf{0 . 8 5}-\mathbf{0 . 9 0}$ & $\mathbf{0 . 8 0}-\mathbf{0 . 8 5}$ & $\mathbf{0 . 7 5}-\mathbf{0 . 8 0}$ \\
\hline CWf & 4 & 3 & 2 & 1 \\
\hline
\end{tabular}

The RII scores and the weights for the various Concepts are shown in Table 3.

Table 3: Practices, their RII Scores and Concept Weights

\begin{tabular}{|l|c|c|}
\hline \multicolumn{1}{|c|}{ Concepts } & RII & Concept Weights (CWf) \\
\hline Physical Manifestation & & \\
\hline 1. Implementation of Lean Tools \& Processes & 0.87 & 3 \\
\hline 2. Continuous Improvement & 0.93 & 4 \\
\hline 3. Focus on Value Creation & 0.84 & 2 \\
\hline 4. Work Standardization & 0.77 & 1 \\
\hline Behavioral Manifestation & & \\
\hline 5. Lean Culture \& Behavior & 0.89 & 3 \\
\hline 6. Waste Identification\& Productivity & 0.81 & 2 \\
\hline 7. People Development & 0.90 & 4 \\
\hline Strategic Manifestation & & \\
\hline 8. Collaborative Working & 0.89 & 3 \\
\hline 9. Strategic Use of Lean & 0.88 & 3 \\
\hline 10. Leadership to drive Lean & 0.85 & 3 \\
\hline 11. Customer Focus & 0.91 & 4 \\
\hline
\end{tabular}


In the second step a Consolidated Stage Score (CSS) is obtained for each Stage as follows:

$\mathrm{CSS}=\sum(\mathrm{PSi} \times \mathrm{CWfi}) / \sum(\mathrm{CWfi})$, where PSi is the Lean Practice Score for each Concept obtained from the Lean Evaluation Checklist and CWfi is the Concept Weight Factorfor that Concept, with "i" summed up over the number of Concepts for each of the three Stages. Thus three CSS numbers covering the three Concepts will be obtained for each of the three Stages.

In the third step the Maturity Level of each Stage is factored in by using a Stage Weight Factor (STF). Duly recognizing that the final LCMR is a summation of the individual scores covering all the Concepts of all the Stages and at the same time recognizing that the higher Stages should have higher scores for the Concepts relevant to the higher stages, the LCMR is derived as follows:

$\mathrm{LCMR}=\sum(\mathrm{CSSj} x \mathrm{STFj})$, with " $\mathrm{j}$ " summed up for the Concepts of the three Stages. Depending on exactly in which Stage a particular Project figures, the STFs will vary for the three Stages, as follows (Figure 3 and Table 4).Hence determination of STFs is somewhat iterative. The curve shown in Figure 3 is depicted as a Learning Curve. Quantitatively, based on various interviews it has been postulated that at end of Stage I Maturity the Lean Construction Maturity Rating corresponds to 4, at end of Stage II it is 7 and at the end of stage III it is 10 . Theoretically there is no upper limit to the maturity level, which keeps improving with "Continuous Improvement". The above is also validated to some extent in the limited number of detailed studies made at some sites.
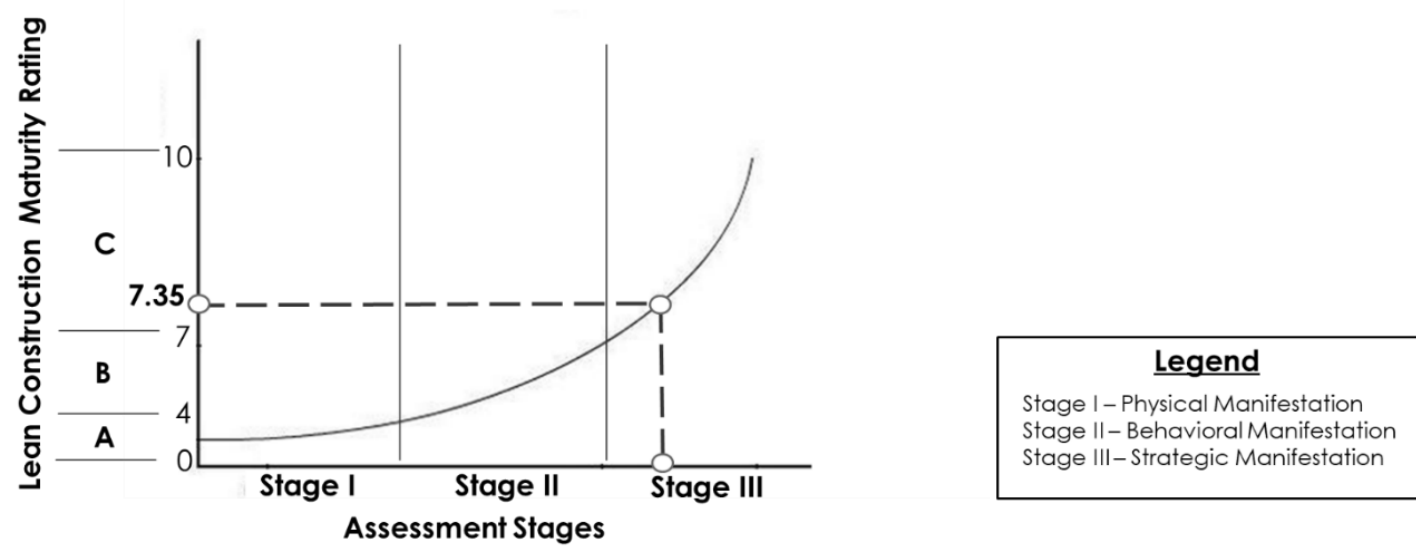

Figure 3: Lean Maturity Progression Curve

Table 4: STF percentages for the three Stages for various LCMR ranges

\begin{tabular}{|c|c|c|c|c|}
\hline & & \multicolumn{3}{|c|}{ STFj } \\
\hline Zone & LCMR & Stage I & Stage II & Stage III \\
\hline A & $0-4$ & $70 \%$ & $20 \%$ & $10 \%$ \\
\hline B & $4-7$ & $55 \%$ & $25 \%$ & $20 \%$ \\
\hline C & $7-10$ & $40 \%$ & $30 \%$ & $30 \%$ \\
\hline
\end{tabular}


LCMR is evaluated by trial and error. Initially it is assumed that the Project would be in Zone A and the STF percentages are applied accordingly. If the resulting LCMR is not compatible with Zone A, i.e. it is not within the range of 0 to 4 then Zone B percentages are tried out and then Zone $C$ percentages, till convergence is reached for one of the three Stages. Thus the final LCMR is obtained.

\section{Sample Data}

The model starts with Lean Evaluation Checklist where all the Concepts, Practices and Attributes are defined.Figure 2 above, shows a sample for Collaborative Working as a Concept, the Attributes which come under this Concept and the Processes which pertain to the Practices. These are scored as 1 or 0 depending on the observations. Table 5 shows all the 11 Concepts which further drop down to 63Practices under 3 stages making it $3 \mathrm{x}$ 11 x 63 matrix for defining Lean Construction Maturity Rating.

In the above Figure2, we can see 4 'yes' out of 6 practices. When normalized to 10, it converts to 6.67 (which can be seen in table below). Table 5 shows the working for some sample data. The second column shows the Concept Weights CWfi and the last column shows the Scores Psi for the various Concepts as well as the CSSj for each of the three stages.

Table 5: Sample data and working of scoring system

\begin{tabular}{|l|c|c|}
\hline \multicolumn{1}{|c|}{ Concepts } & CWfi Weights & Psi Score \\
\hline Physical Manifestation & & $\mathbf{8 . 1}(\mathbf{C S S j})$ \\
\hline 1. Implementation of Lean Tools \& Processes & 3 (Wfi) & $7.33(\mathrm{PSi})$ \\
\hline 2. Continuous Improvement & 4 & 8 \\
\hline 3. Focus on Value Creation & 2 & 10 \\
\hline 4. Work Standardization & 1 & 6.67 \\
\hline Behavioral Manifestation & 3 & $\mathbf{7 . 5}$ \\
\hline 5. Lean Culture \& Behavior & 2 & 7.5 \\
\hline 6. Waste Identification \& Productivity & 4 & 5 \\
\hline 7. People Development & 3 & 10 \\
\hline 8. Collaborative Working & & 6.67 \\
\hline Strategic Manifestation & 3 & $\mathbf{6 . 3}$ \\
\hline 9. Strategic Use of Lean & 3 & 7.5 \\
\hline 10. Leadership to drive Lean & 4 & 5 \\
\hline 11. Customer Focus & & 6.67 \\
\hline
\end{tabular}

As per default Zone A, the LCMR would be $=(8.1 \times 0.7)+(7.5 \times 0.2)+(6.3 \times 0.1)=$ 7.77

But as the LCMR lies in the range of $7-10$, Zone $\mathrm{A}$ is not applicable and Zone $\mathrm{C}$ weightsare applied, i.e. $\mathrm{LCMR}=(8.1 \times 0.4)+(7.5 \times 0.3)+(6.3 \times 0.3)=7.35$

To check, Zone $\mathrm{B}$ weightsare applied, i.e. $\mathrm{LCMR}=(8.1 \times 0.55)+(6.6 \times 0.25)+(6.3 \mathrm{x}$ $0.2)=7.56$. Here as LCMR does not lie in the range of $4-7$, Zone B classification isnot applicable.

From above, LCMR with Zone $\mathrm{C}$ weights converges within the range $(7-10)$. Therefore the final LCMR = 7.35 $($ Ref Figure 3) 
The Project people can also get some idea of the areas in which they are strong in Lean practices and the areas which need to be developed further. The following Bar Graph (Figure 4) or the Spider Radar Diagram (Figure 5) give an idea for the same.

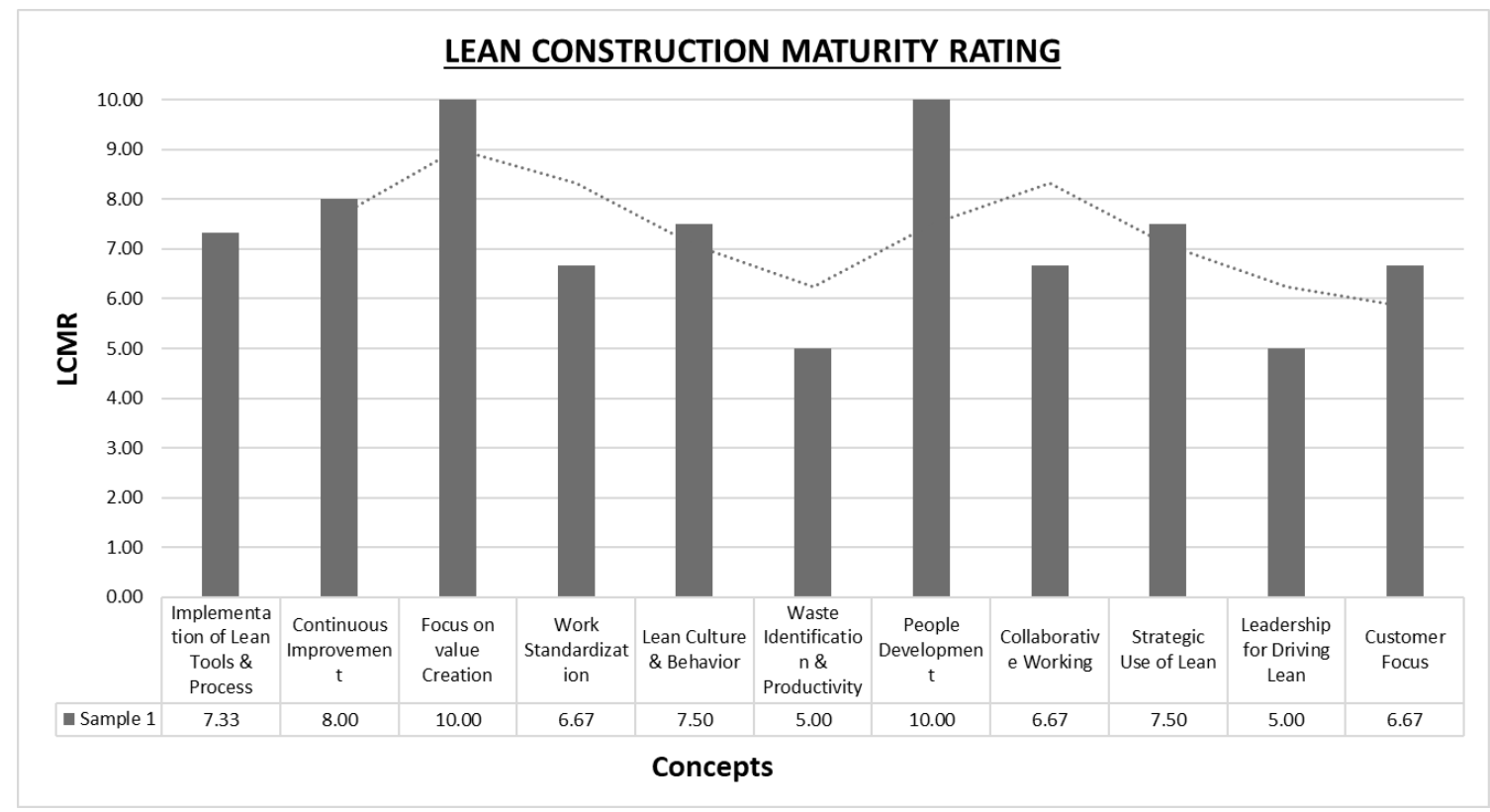

Figure 4: Lean Construction Maturity Rating - Bar Graph representation

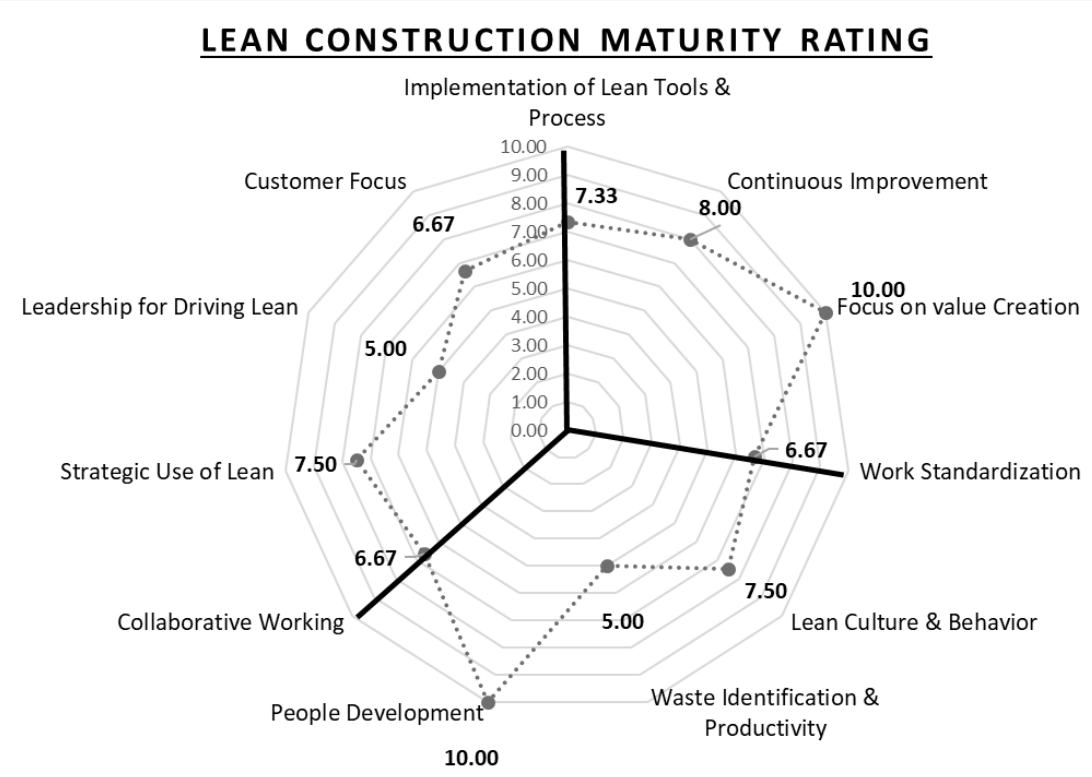

Figure 5: Lean Construction Maturity Rating- Spider-Radar Graph representation 


\section{LIMITATIONS}

All the parameters of Lean might not be convertible to quantifiable scales and some of the Practices considered under each Concept might be project specific or need some more detailing to draw up the Attributes. Also, the fruitfulness of Lean Implementation can only be realized over longer periods of time at enterprise level, rather than at project levels and tangible benefits associated with Lean may not manifest in short term projects. More work is required to validate the model for assessing Lean Maturity at organizational levels, rather than at project levels.

For future works on this topic more thorough engagements with Lean practitioners to capture salient attributes which add to Lean Maturity as well as overall qualitative insights from seasoned Lean experts for a particular Project or organization to validate the quantitative derivations under this framework would be highly beneficial to further validate this model.

\section{CONCLUSION}

This framework provides a means to measure the current state of Lean maturity to determine the prevailing degree of Leanness and to understand the areas requiring improvement. It also helps to a degree in determining the organizational maturity in totality, in the form of physical, behavioral and strategic manifestations.

This model would also help an organization to focus on qualitative aspects such as people development, culture building and strategic leadership to drive Lean, apart from the usual implementation of Lean tools and processes as only tools or only culture cannot bring about the changes that construction industry requires so badly. Appropriately designed training programmes and workshops can be conducted to sensitize the industry and the construction personnel to realize the aspects which contribute to Lean Maturity and help them learn the processes to go further on the path of Lean Maturity.

\section{ACKNOWLEDGEMENT}

The authors wish to thank the various Lean practitioners for spending their valuable time in reviewing and providing feedback for this work.

\section{REFERENCE}

Bernardo M. B. S. Etges, Tarcisio A. Saurin and Iamara R. Bulhões3, A protocol for assessing the use of Lean construction practices.

Etges, B. M. B. S.; Saurin, T. A.; Bulhões, I. R.; (2012). Identifying Lean construction categories of practices in IGLC Proceedings. Proc. for the 20th Annual Conference of the International Group for Lean Construction. San Diego, USA.

Highways Agency (2010). Highways Agency Lean Maturity Assessment Toolkit (HALMAT), Highways Agency Publications, Birmingham, UK. (http://www.highways.gov.uk/publications/Lean-Halmat) 
Hines, P., Holweg, M. \& Rich, N., 2004. Learning to Evolve - A review of contemporary Lean thinking. International Journal of Operations and Production Management, 24(10), pp. 994-1011.

Hofacker, A.; Fernandes, B.; Gehbauer, F.; Carmo Duarte Freitas, M.; Mendes, R.; Santos, A.; Kirsch, J. (2008). Rapid Lean construction - Quality Rating Model. Proc. of the 16th Annual Conference of the International Group for Lean Construction Manchester, UK.241-250.

Hung-da Wan \& F. Frank Chen (2008) A leanness measure of manufacturing systems for quantifying impacts of Lean initiatives, International Journal of Production Research, $46: 23,6567-6584$

LAI-MIT, 2001. Lean Enterprise Self-Assessment Tool - Facilitator's Guide. s.l.:Massachusetts Institute of Technology.

LESAT, 2001. Lean Enterprise Seplf Assessment Tool - Facilitator's Guide. s.l.: Lean Aerospace Initiative - Massachusetts Institute of Technology.

Nesensohn, C. (2017), A Lean Construction Maturity Model for Organization. LC3 Volume II - Proceedings IGLC-25, Heraklion, Greece, pp. 357-363.

Nightingale, D.J., \& Mize, J.H. (2002), Development of a Lean Enterprise Transformation Maturity model. Information Knowledge Systems Management, 3, $15-30$.

Ray, C.D., Zuo, X., Michael, J.H., \& Wiedenbeck, J.K. (2006). The Lean Index: Operational "Lean" Metrics for the Wood Products Industry. Wood and Fiber Science, 38, 238-255.

Sánchez, A.M., \& Pérez, M.P. (2001). Lean indicators and manufacturing strategies. International Journal of Operations \& Production Management, 21, 1433-1452.

Wieslaw Urbana, * (2015). The Lean Management Maturity Self-Assessment Tool Based on Organizational Culture Diagnosis. Procedia - Social and Behavioral Sciences 213 (2015) $728-733$. 